\title{
Efek Sabar dan Syukur Terhadap Penyesuaian Pernikahan
}

\author{
Nafira Zuliana \& Anisia Kumala \\ Fakultas Psikologi Universitas Muhammadiyah Prof. Dr. Hamka \\ nafirazuliana@gmail.com, anisiakumala@gmail.com
}

\begin{abstract}
One of the keys to achieving a quality of marriage is the marital adjustment. Marital adjustment is defined as the process of mutual adjustment between husband and wife in all aspects of their life. There are many challenges faced, so it requires patience and gratitude. Patience is self-control from bad actions, accompanied by an optimistic attitude, never giving up, being open to new information and solutions, and not easily complaining. Meanwhile, gratitude can be defined as positive feelings to oneself, others, the environment and even God, and is expressed in behavior. This study aimed to explore effect of patience and gratitude on marital adjustment. The research approach used is quantitative, involving 203 respondents $($ male $=64$, female $=139)$, taken by purposive sampling technique. Criteria of respondent are married Muslim, age of marriage between 0-2 years. The scale used in this study is the RDAS (Revision Dyadic Adjustment Scale) for marital adjustments with 0.796 reliability, the Patience Scale with 0.749 reliability and the Gratitude Scale in Islamic Psychology with a reliability of 0.839. Statistical analysis techniques use multiple regression. The results of this study indicate an $F$ value of 18,717 with a probability value of 0.000 $(p<0.05)$. This data shows that the variables of patience and gratitude have an effect on marital adjustments by 15.8 percent, or with the $R$ square coefficient $\left(R^{2}\right)$ value of 0.158 .
\end{abstract}

Keywords: Marital Adjustment, Patience, Gratitude

\begin{abstract}
Abstrak
Salah satu kunci dari tercapainya kualitas pernikahan adalah adanya penyesuaian pernikahan. Penyesuaian pernikahan didefinisikan proses saling menyesuaikan antara suami dan istri pada seluruh aspek kehidupannya. Pada prosesnya banyak tantangan yang dihadapi sehingga membutuhkan variabel sabar dan syukur. Sabar adalah pengendalian diri dari tindakan yang tidak baik, disertai sikap optimis, pantang menyerah, terbuka kepada informasi baru maupun solusi, serta tidak mudah mengeluh. Sedangkan syukur dapat diartikan perasaan positif kepada diri sendiri, orang lain, lingkungan dan bahkan Tuhan dan diekspresikan dalam perilaku. Penelitian ini berupaya untuk melakukan studi tentang pengaruh sabar dan syukur terhadap penyesuaian pernikahan. Pendekatan penelitian yang digunakan adalah kuantitatif, melibatkan 203 responden (Laki-laki=64, Perempuan=139), diambil dengan teknik purposif, dengan kriteria yang sudah menikah, Muslim, usia pernikahan 0-2 tahun. Adapun skala yang digunakan pada penelitian ini adalah RDAS (Revision Dyadic Adjustment Scale) untuk penyesuaian pernikahan dengan reliabilitas 0.796, Skala Sabar dengan reliabilitas 0.749 dan Skala Syukur dalam Psikologi Islam dengan reliabilitas sebesar 0.839. Teknik Analisa statistik menggunakan multiple regression. Hasil penelitian ini menunjukan adanya nilai $\mathrm{F}$ sebesar 18.717 dengan probabability value sebesar $0.000(\mathrm{p}<0.05)$. Data ini menunjukkan bahwa variabel sabar dan syukur memberikan pengaruh terhadap penyesuaian pernikahan sebesar 15,8 persen, atau dengan nilai koefisien $\mathrm{R}$ square $\left(\mathrm{R}^{2}\right)$ sebesar 0.158
\end{abstract}

Kata Kunci : Penyesuaian Pernikahan, Sabar, Syukur. 


\section{Pendahuluan}

M Masa dewasa awal adalah masa transisi dari segi fisik, kognitif, maupun sosioemosi dari masa remaja menuju dewasa. Rentang usia masa dewasa awal adalah 18 tahun hingga 40 tahun, dan pada masa ini adalah masa untuk bekerja, jatuh cinta, dan menikah (Santrock, 2012). Setiap pasangan yang menikah, pasti menginginkan hubungan yang harmonis dalam pernikahannya. Hubungan yang harmonis akan membawa pasangan untuk saling memahami, menghargai dan pada akhirnya dapat mengatasi problem bersama (Yani, 2018).

Namun pada kenyataannya tidak semua pasangan yang menikah hidup rukun dan harmonis. Badan Pusat Statistik mengungkapkan bahwa pada tahun 2012 di Indonesia terjadi perceraian sebanyak 346.480 pasangan, pada tahun 2013 terjadi perceraian sebanyak 324.247 pasangan, pada tahun 2014 terjadi peningkatan menjadi 344.237 pasangan, dan pada tahun 2015 meningkat kembali menjadi 347.256 pasangan (www.bps.go.id). Perceraian merupakan salah satu dampak dari ketidak berhasilan seseorang melakukan penyesuaian diantara pasangan suami istri (Karlina dkk, 2013). Ketika kedua pasangan mudah untuk melakukan penyesuaian diantara keduanya, mereka akan lebih mudah untuk mempertahankan hubungan pernikahannya.

Atwater (dalam Karlina dkk, 2013) menyatakan bahwa pada dasarnya pernikahan merupakan media saling memahami dan saling menyesuaikan. Konsep penyesuaian pernikahahan berbeda dengan kepuasan pernikahan. Spanier dan Cole (dalam Kendrick dkk, 2016) menyatakan bahwa kepuasan pernikahan menggambarkan seberapa puas setiap pasangan dalam hubungan pernikahan, sedangkan penyesuaian pernikahan menjelaskan berbagai komponen, termasuk kepuasan pernikahan, dan digunakan untuk memprediksi kesuksesan pernikahan.

Tahun awal pernikahan adalah masa kritis karena pasangan belum banyak memiliki pengalaman bersama. Hurlock (dalam Shella \& Rangkuti, 2013) bahkan menjelaskan bahwa dua tahun pertama sangat diperlukan penyesuaian dengan pasangan dan dengan kolega lainnya. Parker (dalam Latifa, 2015) menyatakan bahwa penyesuaian pada awal pernikahan merupakan penyesuaian dari berbagai hal yang disukai maupun kebiasaan buruk pasangan. Bukan hanya itu, setiap pasangan harus menyesuaikan segala macam hobi, kebiasaan, pendapat, dan hal-hal lain yang dapat mempengaruhi kehidupan berumah tangga.

Spanier (Puspitasari dkk, 2014) menyatakan bahwa penyesuaian pernikahan merupakan proses yang berkesinambungan setiap saat yang menghadirkan keseimbangan antara dimensi-dimensi dalam penyesuaian pernikahan, seperti; Dyadic Satisfaction (kepuasan), Dyadic Cohesion (kedekatan), Dyadic Consensus (kesepahaman atau kesepakatan), Afection Expression (menyatakan kasih sayang). Penyesuaian pernikahan akan terjadi setiap waktu, dan akan menentukan kesuksesan dalam hubungan pernikahannya.

Dyadic Consensus (kesepahaman atau kesepakatan) yaitu tingkat kesepahaman atau kesepakatan diantara pasangan dalam mengatasi berbagai masalah dalam pernikahan, dengan begitu diperlukan adanya sikap sabar pada tiap individu. Sedangkan, Dyadic Satisfaction (kepuasan), Dyadic Cohesion (kedekatan), Afection Expression (menyatakan kasih sayang) diperlukan adanya rasa syukur. Sabar dan syukur memang saling berkaitan, karena individu tidak akan bisa dikatakan bersabar kalau ia tidak bersyukur dan begitu juga sebaliknya, ia tidak bisa dikatakan bersyukur jika ia tidak bersabar (Ridjaluddin, 2009).

Sabar, secara bahasa diartikan sebagai mengendalikan (diri). Adapun menurut syar'i sabar diartikan sebagai pengendalian diri dalam konteks ketaatan kepada perintah Allah maupun larangan-Nya, dan menerima takdir Allah yang tidak sesuai dengan keinginan. (Junaedi, 2013). 
Dengan adanya rasa sabar dalam pernikahan, setiap pasangan akan selalu menahan diri untuk tidak melakukan hal buruk sehingga keduanya berusaha untuk tidak saling menyakiti satu sama lain. Dalam buku yang berjudul "Bila mampu, Menikahlah! Bila tidak, Berpuasalah" disebutkan bahwa sabar adalah tanda kedua bagi orang yang sudah mampu secara mental untuk menikah (Rokhim, 2015).

Pasangan suami istri harus mempunyai sikap sabar didalam diri. Menurut Turfe (dalam Kamaliyah, 2008) sabar akan berimplikasi pada kekuatan dalam menghadapi problem perkawinan. Dalam membina kehidupan berumah tangga, suami istri dituntut untuk saling bersabar menghadapi kekurangan masing-masing, bersabar menanggung beban masing-masing sehingga dapat mempertahankan kelestarian rumah tangga dengan suasana bahagia dan harmonis (Effendi dkk, 2013).

Menurut El Hafiz (2015) sabar adalah respon pertama dan aktif untuk menahan emosi, perasaan, perkataan dan perbuatan sesuai dengan aturan, sehingga memunculkan kebaikan. Sabar juga mengandung makna optimis, tidak mudah menyerah, berupaya terus menggali informasi/ilmu, serta bersikap terbuka untuk menemukan solusi, konsisten dan pantang mengeluh. Sabar bukan hanya sekedar berdiam diri, tetapi penuh kreatifitas, keteguhan, optimis jiwanya, tidak mudah terombangambing keadaan, dan tetap mengambil keputusan serta tindakan secara bijaksana walaupun dalam keadaan yang sulit sekalipun (Ridjaluddin, 2009). Bersabar dalam proses penyesuaian pernikahan, tidak membuat setiap pasangan menjadi lemah, tetapi menjadi individu yang bijaksana serta selalu mencari informasi/ilmu, terbuka terhadap solusi dalam menghadapi setiap permasalahan, dan optimis dalam mempelajari hal-hal baru bersama pasangan, serta tidak mudah mengeluh yang hal itu juga lebih dekat kepada syukur.

Syukur atau dalam bahasa arab "al-syukur" bermakna "terima kasih", dan secara lingustik bermakna pujian atas kebaikan yang telah diberikan (Nasharudin, 2015). Dalam bahasa Arab, syukur bermakna pujian atau apresiasi karena adanya kebaikan yang didapatkan (seperti rasa ridha atau puas dengan apapun yang diperoleh). Syukur juga berarti adanya perasaan bahwa kebutuhannya telah terpenuhi dibarengi dengan ketabahan (Listiyandini dkk, 2015). Ketabahan dapat dikatakan sebagai sabar, dari pernyataan tersebut dapat dipahami bahwa setiap manusia dapat dikatakan bersyukur jika ia mampu untuk bersabar.

Jika melihat dari American Heritage Dictionary of The English Language (dalam Listiyandini dkk, 2015) syukur diambil dari kata Latin, gratus/gratitude, berarti berterima kasih atau pujian, dan konstruk gratitude yang dibangun oleh McCullough et al (2002) meliputi thankfulness, gratefulness, dan appreciative. Dalam dimensi psikologis, syukur meliputi rasa kagum, rasa berterimakasih dan juga penghargaan akan kehidupan (Putra, 2014). Menurut Emmons (dalam Putra, 2014) berpendapat bahwa perasaan tersebut dapat ditujukan kepada pihak lain, baik terhadap sesama manusia, Tuhan, atau mahluk hidup lain.

Pasangan yang mudah bersyukur akan selalu menghadirkan kebahagiaan, rasa cinta, dan kasih sayang dalam hubungannya. Sebab, syukur terwujud sebagai pujian, rasa cinta dan kasih saying kepada pasangan (Syamsuddin, 2009). Menurut penelitian Emmons \& Crumpler, 2002; Emmons \& McCullough, 2003; McCullough, Emmons, Tsang, 2004; Watkins, Cruz, Holben, \& Koltz, 2008 (dalam Parnell, 2015) individu yang bersyukur akan menerima banyak manfaat, termasuk peningkatan makna dalam hidup, optimis, bahagia, dan energy, serta hubungan yang baik dengan orang lain.

Syukur bukan hanya dikaji berdasarkan pandangan tokoh agama, melainkan tokoh-tokoh psikologi juga mengkaji tentang rasa syukur. Islam mengajarkan syukur baik secara vertical 
maupun horizontal, namun psikologi barat lebih cenderung menerjemahkan syukur pada dimensi horizontal (Rusdi, 2016). Dalam konsep syukur murni yang diajarkan Islam yang disebutkan oleh Al Fauzan (dalam Putra, 2014) bersyukur meliputi komponen dengan hati, lisan, dan perbuatan. Dalam buku "Psikologi Keluarga Islam" disebutkan bahwa untuk mewujudkan dan melestarikan keluarga sakinah setiap pasangan harus selalu bersyukur saat mendapatkan nikmat dan senantiasa bersabar saat ditimpa kesulitan (Mufidah, 2008).

Dari uraian diatas, peneliti mengasumsikan bahwa sabar dan syukur dapat mempengaruhi penyesuaian pernikahan masa 2 tahun pertama pernikahan. Dengan begitu, peran sabar adalah menahan segala hal yang tidak disukai dari pasangan tetapi tetap semangat dan terus belajar untuk saling memahami fungsi peran dan tanggung jawab masing-masing, dan syukur lebih kepada sikap menikmati segala hal yang terjadi didalam pernikahan dan menyadari bahwa setiap manusia memiliki sisi baik dan buruknya masing-masing. Dengan ini, judul pada penelitian ini adalah "Pengaruh Sabar dan Syukur terhadap Penyesuaian Pernikahan pada Masa 2 Tahun Pertama Pernikahan".

\section{Metode}

Partisipan

Penelitian ini menggunakan purposive sampling sebagai teknik pengambilan sample. Kriteria responden adalah laki-laki maupun perempuan yang sudah menikah, dengan usia pernikahan 0 bulan-2 tahun, beragama islam, dan berada pada masa dewasa awal yaitu berusia 18-40 tahun. Adapun jumlah sampel pada penelitian ini berjumlah 139 perempuan dan 64 laki-laki.

\section{Analisa Data}

Teknik analisa data yang digunakan pada penelitian ini untuk menganalisa data dengan menggunakan teknik multiple regression, teknik ini untuk mengetahui peran dari sabar dan syukur dalam penyesuaian pernikahan.

Alat ukur yang digunakan dalam studi ini, yaitu:

1. Revision of The Dyadic Adjustment Scale (Busby et al, 1995) untuk penyesuaian pernikahan. Alat ukur ini adalah hasil perbaikan dari Dyadic Adjustment Scale yang dibuat pertama kali oleh Graham B. Spanier pada tahun 1976. Terdapat 14 item pada alat ukur ini, dengan reliabilitas Cronbach Alpha sebesar 0,796.

2. Peneliti menggunakan alat ukur sabar yang disusun oleh El Hafiz (2015). Terdapat 16 item pada alat ukur ini, dengan reliabilitas Cronchbach's Alpha sebesar 0,749.

3. Peneliti menggunakan alat ukur syukur yang dikembangkan oleh Rusdi (2016). Terdapat 13 item pada penelitian ini, dengan reliabilitas Cronbach Alpha sebesar 0,839. 


\section{Hasil Penelitian}

Uji Korelasi

Tabel 1. Korelasi Sabar dan Syukur terhadap Penyesuaian Pernikahan

\begin{tabular}{lll}
\hline Variabel & Pearson & Sig \\
Correlation &
\end{tabular}

\begin{tabular}{lll}
\hline Sabar dengan Penyesuaian Pernikahan & .327 & $\mathbf{. 0 0 0}$ \\
Syukur dengan Penyesuaian Pernikahan & .330 & $\mathbf{. 0 0 0}$
\end{tabular}

Pada tabel 1 dapat kita lihat bahwa pearson correlation sabar dengan penyesuaian pernikahan sebesar .327, dan pearson correlation syukur dengan penyesuaian pernikahan sebesar .330 yang berarti korelasi sabar dan syukur terhadap penyesuaian pernikahan memiliki hubungan positif sedang. Sedangkan, sig sabar dengan penyesuaian pernikahan maupun syukur dengan penyesuaian pernikahan sebesar .000. Berdasarkan dari hasil yang sudah didapat, kesimpulannya adalah :

1. Sabar dan penyesuaian pernikahan memiliki koefisien korelasi positif, karena nilai pearson correlation .327 , dengan nilai $\mathrm{P}=.000(\mathrm{P}<0.01)$ Hal ini menunjukkan bahwa hubungannya positif signifikan.

2. Syukur dan penyesuaian pernikahan memiliki koefisien korelasi positif, karena nilai pearson correlation .330 , dengan nilai $\mathrm{P}=.000(\mathrm{P}<0.01)$ menunjukkan hubungan positif yang signifikan.

\section{Uji Regresi}

Pada penelitian ini, peneliti menggunakan analisa statistik Multiple Regression untuk mengetahui pengaruh sabar dan syukur terhadap penyesuaian pernikahan. Berikut merupakan hasil yang sudah peneliti dapatkan :

Tabel 2 Anova

F Sig
18.717
0.000

Berdasarkan tabel 2, nilai F 18.717 dengan probability value sebesar $0.000(<0.01)$ menunjukan bahwa nilai F signifikan. Artinya Ha diterima, yaitu adanya pengaruh yang signifikan antara sabar dan syukur terhadap penyesuaian pernikahan.

Tabel 3 Hasil Regresi Sabar dan Syukur terhadap Penyesuaian Pernikahan

\begin{tabular}{lll}
\hline $\mathbf{R}$ & R Square & Sig.F Change \\
\hline .397 & .158 & .000 \\
\hline
\end{tabular}


Berdasarkan tabel 3, hubungan sabar dan syukur dengan penyesuaian pernikahan diperoleh nilai korelasi (R) sebesar 0.397 dan nilai R Square sebesar 0.158. Berdasarkan hasil yang sudah didapat, variabel sabar dan syukur memberikan pengaruh terhadap penyesuaian pernikahan sebesar 15.8.\% dan tingkat signifikan sebesar 0.000 yang berarti $\mathrm{P}<0.01$ dan artinya signifikan.

Tabel 4 Koefisien

\begin{tabular}{clll}
\hline Model & B & T & Sig \\
\hline 1. (Constant) & 24.889 & 4.596 & 0.000 \\
Sabar & 0.351 & 3.397 & 0.001 \\
Syukur & & & \\
& 0.166 & 3.473 & 0.001 \\
\hline
\end{tabular}

Berdasarkan tabel 4, diketahui bahwa nilai Unstandardized Beta sebesar 0.351 dengan probability value sebesar $0.001 \quad(<0.01)$, berarti ada efek positif yang signifikan antara sabar terhadap penyesuaian pernikahan. Sehingga semakin tinggi sabar, maka semakin mudah untuk melakukan penyesuaian pernikahan. Selanjutnya pada nilai Unstandardized Beta sebesar 3.473 dengan probability value sebesar $0.001(<0.01)$ yang berarti ada efek positif yang signifikan antara syukur terhadap penyesuaian pernikahan, sehingga semakin seseorang merasa bersyukur ada, maka semakin mudah pula mereka melakukan penyesuaian pernikahan.

\section{Diskusi}

Pada penelitian ini, analisa data yang telah dilakukan memperoleh hasil bahwa terdapat hubungan yang signifikan antara sabar dan penyesuaian pernikahan pada pasangan yang berusia 0 bulan-2 tahun. Sabar dan penyesuaian pernikahan memiliki koefisien korelasi positif yang signifikan, yaitu dengan nilai pearson correlation 0.327 dengan nilai $\mathrm{P}=0.000(<0.01)$. Pada syukur dan penyesuaian pernikahan juga memiliki koefisien korelasi positif yang signifikan, yaitu dengan pearson correlation 0.330 dengan nilai $\mathrm{P}=0.000(<0.01)$.

Berdasarkan hasil analisis penelitian yang sudah dilakukan, uji hipotesis pada penelitian ini diterima. Hal ini dapat diketahui berdasarkan nilai $F$ sebesar 18.717 dengan $\mathrm{P}=0.000(<0.01)$, dan dapat disimpulkan bahwa sabar dan syukur memiliki pengaruh yang signifikan terhadap penyesuaian pernikahan. Koefisien korelasi pada penelitian ini sebesar 0.397 dan R square 0.158 yang berarti $15,8 \%$ kontrubusi variabel sabar dan syukur terhadap penyesuaian pernikahan, sedangkan $84,2 \%$ dari variabel lain tidak diketahui pada penelitian ini.

Hasil ini didukung oleh pernyataan dalam buku "Psikologi Keluarga Islam" disebutkan bahwa untuk mewujudkan dan melestarikan keluarga sakinah setiap pasangan harus selalu bersyukur saat mendapatkan nikmat dan senantiasa bersabar saat ditimpa kesulitan (Mufidah, 2008). Selain itu, pada penelitian sebelumnya yang dilakukan oleh Handayani (2017) dengan judul "Pengaruh Sabar dan Syukur terhadap Keharmonisan Keluarga yang Bekerja", mendapatkan hasil bahwa keharmonisan keluarga terbentuk karena sabar dan syukur sebesar 14,1\%. Dalam penelitian 
Handayani (2017) hasil tersebut didukung oleh pendapat dari @sobat_loversh (2004) yang menyatakan bahwa kunci keberhasilan mengarungi biduk pernikahan adalah sabar dan syukur.

Selanjutnya, pada penelitian yang dilakukan oleh Kumala \& Trihandayani (2015) dengan judul "Peran Memaafkan dan Sabar dalam Menciptakan Kepuasan Perkawinan", mendapatkan hasil bahwa sabar berperan secara signifikan dalam kepuasan perkawinan, dengan nilai signifikansi 0.000 (<0.01). Besaran pengaruh sabar terhadap kepuasan perkawinan adalah $15.3 \%$. Dalam penelitian ini disebutkan bahwa dengan sabar pasangan suami istri dapat bertahan untuk menyelesaikan problem perkawinan mereka dengan aktif mendapatkan beragam alternatif solusi. Karena, sabar dalam penelitian El Hafiz (2015) bukan berarti pasrah, melainkan mengendalikan perasaan, pikiran, perkataan dan perbuatan untuk tujuan yang baik, diiringi dengan optimisme, sikap tidak mudah menyerah dan terbuka terhadap segala alternatof solusi.

Penelitian Kamaliyah \& Kurniawan (2008) yang berjudul "Hubungan Kesabaran dengan Memaafkan dalam Pernikahan" menyatakan bahwa hubungan keduanya signfikan dengan nilai $\mathrm{r}=$ 0.755. Hal ini mengndikasikan bahwa kesabaran dan memaafkan dalam pernikahan hubungan positif. Dalam penelitian tersebut, didukung oleh pernyataan dari Jauziyah (2006) yang menyatakan bahwa penyabar adalah orang yang bisa menahan dirinya dari perbuatan yang tidak menyenangkan bagi orang lain, maupun pasangan, ataupun perbuatan yang ditujukan untuk balas dendam kepada pasangan yang berbuat kesalahan.

Sementara itu, pada penelitian yang dilakukan oleh Karlina dkk (2013) dengan judul "Pengaruh Religiusitas dan Adult Attachment Terhadap Marital Adjustment Pada Pasangan yang Baru Menikah" memperoleh hasil Marital Adustment terbentuk karena Religiusitas dan Adult Attachment sebesar 49,9\%. Dalam penelitian Karlina, dkk (2013) juga disebutkan bahwa pasangan riligius dan memiliki pengalaman spiritual akan merasa tenang, merasa dilimpahi kasih saying Tuhan, diliputi perasaan syukur kepada Tuhannya.

\section{Kesimpulan dan Saran}

\section{Kesimpulan}

Studi ini menyimpulkan bahwa sabar dan syukur berperan dalam penyesuaian pernikahan pada masa 2 tahun pertama usia pernikahan". Hal ini dapat diketahui berdasarkan nilai F sebesar 18.717 dengan nilai $\mathrm{P}=0.000(<0.01)$, dengan demikian, Hipotesa alternatif diterima. Koefisien korelasi pada penelitian ini sebesar 0.397 dan R square 0.158 yang berarti 15,8\% kontrubusi variabel sabar dan syukur terhadap penyesuaian pernikahan, sedangkan $84,2 \%$ dari variabel lain tidak diketahui pada penelitian ini.

\section{Saran}

Dari hasil penelitian yang sudah dilakukan, peneliti menyadari bahwa masih ada kekurangan dalam penelitian ini, oleh sebab itu peneliti memberitahu diantaranya:

\section{Saran Teoritis}

1. Peneliti menyarankan agar pada peneliti selanjutnya melihat perbedaan responden dari segi karakteristik demografi yang dimiliki setiap pasangan.

2. Peneliti menyarankan agar pada penelitian selanjutnya responden tidak hanya yang beragama Islam saja. 
3. Peneliti menyarankan agar pada penelitian selanjutnya menggunakan alat ukur syukur lain yang bisa digunakan untuk semua agama.

\section{Saran Praktis}

1. Disarankan untuk pasangan yang belum dan baru menikah untuk memiliki sikap sabar didalam diri, karena dengan sabar membuat individu lebih optimis, tidak mudah menyerah, dan tenang dalam menghadapi masalah dipernikahan.

2. Disarankan untuk pasangan yang belum dan baru menikah untuk memiliki rasa syukur didalam diri, karena dengan syukur membuat individu lebih bahagia dan menerima pasangan dengan baik tanpa membanding-bandingkan dengan orang lain, sehingga lebih bisa menyesuaikan diri dalam pernikahan.

\section{Daftar Pustaka}

Busby, D. M., Christensen, C., Crane, D. R., \& Larson, J. H. (1995). A revision of the Dyadic Adjustment Scale for use with distressed and nondistressed couples: Construct hierarchy and multidimensional scales. Journal of Marital and Family Therapy, 21(3), 289-308.

Effendi, R., \& Shaleh, K. (2013). Memperbaiki Gonjang-Ganjing Akhlak Bangsa. Al-Fikriis.

El-Hafiz, S., Mundzir, I., Rozi, F., \& Pratiwi, L. (2015). Pergeseran Makna Sabar dalam Bahasa Indonesia. Ilmiah Penelitian Psikologi: Kajian Empiris \& Non-Empiris, 1(1), 33-38.

Junaedi, D. (2013). Berbahagialah. PT Elex Media Komputindo.

Kamaliyah, N., \& Kurniawan, I. N. (2008). Hubungan antara Kesabaran dengan Memaafkan dalam Pernikahan. Fakultas Psikologi dan Ilmu Sosial Budaya UII.

Karlina, R., Avicenna, M., \& Andriani, Y. (2013). Pengaruh Religiusitas dan Adult Attachment Terhadap Marital Adjustment pada Pasangan yang Baru Menikah. Tazkiya Journal of Psychology, 1(2). https://doi.org/10.15408/tazkiya.v1i2.10682

Kendrick, H. M., \& Drentea, P. (2016). Marital Adjustment. Encyclopedia of Family Studies, 1-2. https://doi.org/10.1002/9781119085621.wbefs071

Kumala, A., \& Trihandayani, D. (2015). Peran Memaafkandan Sabar dalam Menciptakan Kepuasan Perkawinan. Jurnal Ilmiah Penelitian Psikologi: Kajian Empiris \& Non-Empiris, 1(1), 3944. 
Latifa, R. (2015). Komitmen Beragama Islam Memprediksi Stabilitas Pernikahan. Komitmen Beragama Islam Memprediksi Stabilitas Pernikahan, 3(1). https://doi.org/10.15408/tazkiya.v20i1.9191

Listiyandini, R. A., Nathania, A., Syahniar, D., Sonia, L., \& Nadya, R. (2017). Mengukur rasa syukur: Pengembangan model awal Skala Bersyukur versi Indonesia. Jurnal Psikologi Ulayat, 2(2), 473-496. https://doi.org/10.24854/jpu39

Mufidah. (2008). Psikologi Keluarga Islam Berwawasan Gender.

Nashruddin, H. (2015). Akhlak: Ciri Manusia Paripurna. Rajawali Pers.

Parnell, K. J. (2015). The Influence Of a Couple Gratitude Intervention On Emotions, Intimacy, And Satisfaction In The Relationship.

Puspitasari, J. R., \& Satiningsih. (2014). Perbedaan Penyesuaian Pernikahan pada Pasangan yang Menikah Muda. Jurnal Psikologi Teori Dan Terapan, 5(1), 45-51.

Putra, J. S. (2014). Syukur: Sebuah konsep psikologi indigenous islami. Jurnal Soul, 7(2), 35-44. Ridjaluddin, F. N. (2009). Sabar dalam Pandangan Imam Al-Ghazali. Lembaga Kajian Islam. Rokhim, N. (2015). Bila Mampu, Menikahlah! Bila Tidak, Berpuasalah! DIVA Press.

Rusdi, A. (2016). Syukur dalam Psikologi Islam dan Konstruksi Alat Ukurnya. NASPA Journal, $4(4), 95-117$.

Shella, S., \& Rangkuti, A. A. (2013). Pengaruh Trait Kepribadian Terhadap Penyesuaian Perkawinan Pada Dewasa Awal Usia Perkawinan 1-5 Tahun. In JPPP - Jurnal Penelitian dan Pengukuran Psikologi (Vol. 2, Issue 2, p. 112). https://doi.org/10.21009/jppp.022.07

Uyun, Q. (2012). Sabar dan Shalat Sebagai Model Untuk Meningkatkan Resiliensi di Daerah Bencana, Yogyakarta. Jurnal Intervensi Psikologi, 4(2), 253-267.

Yani, I. (2018). Harmonisasi Keluarga Pasangan Suami Istri Yang Tidak Memiliki Keturunan di Desa Bangun Jaya Kecamatan Tambusai Utara Kabupaten Rokan Hulu. 5(1), 1-14. 